\title{
cenizas volantes
}

P. GARCIA DE PAREDES

ícenclado en cienclas químicas

\section{sección de estudios especiales sobre aglomeranfes}

La utilización de las cenizas volantes ocupa, muy a menudo, las páginas de las revistas científicas y técnicas. En el primer semestre de este año han sido publicados diversos trabajos que nos proponemos glosar siguiendo la tradición de nuestro Instituto, cuya Dirección siempre ha dedicado a este tema un destacado interés, como lo demuestran los trabajos y publicaciones del doctor don Demetrio Gaspar Tebar, y entre los cuales destaca la monografia núm. 175, que encierra una exhaustiva revisión de las múltiples aplicaciones de estos materiales, junto con valiosas experiencias propias.

En el primer número de este año de «Betonsteinzeitung», Peters (I) compendia experiencias recogidas en diversos paises, mereciendo destacarse, entre otros, los siguientes resultados:

No todas las cenizas volantes, atendiendo a su composición química, podrían clasificarse en el mismo grupo de aglomerantes de los establecidos por Kühl en su afamada «Química del cementos, ya que, mientras algunas deben poseer propiedades aglomerantes latentes, otras parecen poseerlas «per se». La composición química permite establecer una manifiesta diferencia entre las cenizas procedentes de lignitos y las de antracitas, que más bien recuerdan al Trass.

Se confirma en las cenizas el criterio que va abriéndose paso para el portland en relación a un óptimo de finura que no conviene superar; los valores superiores a los $5.000 \mathrm{~cm}^{2} / \mathrm{g}$ no van acompañados de mejoras sensibles. También, y análogamente a lo ocurrido con las escorias de horno alto, la estima hacia los altos contenidos en alúmina va sustituyendo a la tradicional y preponderante preocupación por una sílice alta.

Recoge y destaca Peters la unánime confirmación del excelente comportamiento de los hormigones, cuyo aglomerante encierra cenizas. frente a las aguas agresivas. Hormigones con cementos que contenian hasta el $40 \%$ de cenizas ricas en alúmina y sílice, resisten, sin disminuir su durabilidad, más de dos años sumergidos en disoluciones con $10 \%$ de sulfato sódico - de $1 \%$ de ácido sulfúrico.

También existe un valor óptimo para el contenido de cenizas capaz de incrementar en forma adecuada la compacidad del hormigón y, en consecuencia, la impermeabilidad; este valor es diferente de unas a otras cenizas y se halla subordinado, en forma no del todo clara, a otras propiedades de las mismas.

La retracción sufre modificaciones por la presencia de cenizas con signo diferente a lo ocurrido al utilizar puzolanas, ya que, a pesar de su finura, provocan disminuciones de retracción, quizás atribuibles a la textura principalmente vítrea de sus granitos; las cenizas menos carbonosas son las que más benefician al hormigón en lo referente a retracción.

Es interesante la propiedad que presentan las cenlzas de exigir, cuando están presentes en un aglomerante, más cantidad de agentes aireantes, para alcanzar un porcentaje dado de aire, que si el aglomerante no contuviese cenizas; es posible que juegue aquí un papel notable la capacidad absorbente del carbón.

Podria temerse que las cenizas, con su aporte de alcalinos, incrementasen los efectos disruptivos de la reacción entre los áridos activos y los álcalis del aglomerante; pero, se da la feliz circunstancia de actuar las cenizas precisamente en forma diametralmente opuesta. ilntervendrá la textura vítrea de las cenizas? Quizás sí, ya que las escorias siderúrgicas de horno alto ejercen también un efecto corrector en las destrucciones provocadas por la magnesla y es posible sean mecanismos similares los que inhiben las dos reacciones tan diferentes. 
Las cenizas incrementan la docilidad de los hormigones más acentuadamente que las puzolanas, lo que era de esperar teniendo en cuenta la forma esférica y la superficie vítrea de los grantitos, $y$, debido a ello, las cenizas de los lignitos superan a las demás en este aspecto.

Como en todas las adiciones puzolánicas, el desarrollo de las resistencias es mis lento en los hormigones que encierran cenizas que en aquéllos de igual dosificación, pero exentos de ellas; en plazo de un año, con cenizas casi exentas de carbón y muy finas, se llegan a igualar las resistencias, incluso con sustituciones del $40 \%$ de portland por cenizas.

La presencia de cenizas en los hormigones no constituye un problema para el curado; en general, es más conveniente el ambiente muy húmedo y poco frío. Como materiales muy silíceos, se portan muy bien al someterios al curado hidrotérmico (autoclave).

Peters aconseja no pasar del $5 \%$ de carbón, y supone que los hormigones con cenizas son especialmente apropiados para las obras masivas $y$ en las que interese una superficie muy compacta, aunque se sacrifiquen algo las resistencias mecánicas.

En febrero del año actual, el número 6 de «Public Roads» ofrece dos artículos dedicados a cenizas volantes. Uno de ellos (2), se refiere a los métodos más adecuados para el ensayo del valor que las cenizas volantes pueden representar como sustitutivos de otros aglomerantes o como adición activa a los aglomerantes tradicionales. Las resistencias alcanzadas por las mezclas portland-cenizas dependen de tres variables: cantidad de carbón incluído en las cenizas, finura de las mismas y cantidad de agua que la mezcla requiere para alcanzar la consistencia normal de ensayo.

Resulta curioso que cada tipo de cenizas desarrolla al máximo su capacidad hidráulica con un determinado tipo de portland; por cierto, que la finura se aprecia en forma más real a través del tamizado sobre la tela de 44 micras que por la superficie «Blaine», ya que, mientras que no se llega a establecer una relación entre la resistencia y la finura «Blaine», sí se observa un aumento en las resistencias paralelo al incremento de finura a través del tamiz.

No aparecen como métodos apropiados para juzgar el valor hidráulico de las cenizas ni la absorción de cal, por contacto prolongado entre cenizas y lechada, ni la reacción de éstas con hidróxido sódico, método empleado en la dis- criminación de los áridos activos a la reacción con los alcalinos del aglomerante. Sin negar valor relativo a los ensayos, se pone de manifiesto la necesidad de mejorar su conocimiento para adaptarlos a estos materiales.

La influencia desagradable del carbón se pone también de manifiesto en este trabajo, cuyos autores la puntualizan en el incremento del agua de amasado que provoca.

Las conclusiones deducidas por el Departamento de Investigaciones Físicas del «Bureau of Public Roads» (3) al ensayar cenizas volantes de procedencias muy dispares, mezcladas con cementos portland de dos tipos, alto en álcalis $y$ bajo en ellos, coinciden bastante con las observaciones de Peters. En general, se advierte que cuarito mayor sea la cantidad de carbón encerrada en las cenlzas, y también mayor la cantidad de éstas empleadas en sustituir al portland, menores son las resistencias mecánicas alcanzadas; a pesar de esta pesimista perspectiva han podido comprobar que, a un año de plazo, los hormigones preparados con aglomerante cemento-cenizas, en las que éstas contenían poco carbón, alcanzaban, e incluso superaban, las resistencias de los hormigones sin cenizas para sustituciones que no rebasen el $30 \%$ de cenizas.

También en este año de 1957 aparecen en dos revistas, belga y francesa (4 y 5), êl resumen extenso de la comunicación presentada a las Jornadas Internacionales de Aglomerantes Hidráulicos, celebradas en Bruselas el mes de junio de 1956, por el presidente de la Sociedad de Materiales de Construeción del Loisne, M. P. Fouilloux. El trabajo tiene la particularidad de marcar una nueva senda en el aprovechamiento de las cenizas volantes, puesto que, mientras en los ensayos o realizaciones comunicadas hasta el presente las cenizas se mezclaban con portland, ahora se trata de mezclas ternarias portlandcenizas-escorias siderúrgicas.

El comunicante expone cómo se le planteó el problema de obtener un cemento puzolánico que careciese del inconveniente de la lentitud, encontrando la solución en la mezcla ternaria ya referida, con tal éxito que el aglomerante ha sido patentado e inscrito en la lista de aquéllos cuyo empleo en aguas salinas es permitido por el Ministerio de Obraș Públicas francés.

Como confirmación de cuanto antecede, resumimos algunos datos de resistencias a la compresión del mortero $1: 3$, tanto del portland usado como de la mezcla binaria cenizas-portland $\chi$ de la ternaria cenizas-portland-escorias, a los siete $y$ veintiocho días: 
$\mathbf{7}$ dias $\quad \mathbf{2 8}$ dias

Portland ......... $273 \mathrm{~kg} / \mathrm{cm}^{2} \quad 438 \mathrm{~kg} / \mathrm{cm}^{4}$ Mezcla binaria ...... $188 \mathrm{~kg} / \mathrm{cm}^{2} \quad 332 \mathrm{~kg} / \mathrm{cm}^{2}$ Mezcla ternaria ..... $296 \mathrm{~kg} / \mathrm{cm}^{2} \quad 508 \mathrm{~kg} / \mathrm{cm}^{2}$

Dotados de un débil calor de hidratación y una excelente resistencia a las aguas con $\mathrm{pH}<7$, estos aglomerantes encuentran su especifica aplicación en los suelos selenitosos, aguas selenitosas, marinas y aciduladas por el carbónico. Se pueden utilizar simultáneamente en fundaciones y superestructuras, evitándose así el peligro de una corrosión de las armaduras largas embebidas en hormigones diferentes.

Buena prueba de cuanto antecede lo constituye el uso de estos aglomerantes en diversas obras, tanto metropolitanas como coloniales, que el autor cita; por cierto, que también subraya la importancia de un contenido alto en alúmina $y$ óxido de hierro, mejor que en silice.
No creo se nos pueda tachar de teóricos si nos permitimos insistir en la necesidad de ensayar las cenizas volantes españolas para conocer mejor sus aplicaciones con los aglomerantes españoles $y$ en el clima hispánico.

\section{BIBLIOGRAFIA}

I. H. PETERS: Betonsteîn Ztg. H. I S. 27. 1957.

2. R. H. BRINK y W. J. HALSTEAD: Public Roads. V. 26, núm. 6, pág. 121. 1957.

3. A. G. TIMMS y W. E. GIEB: Public Roads. V. 26, núm. 6, pág. 142. 1957.

4. P. FOUILLOUX: Rev. des Matériaux, núm. 502, pág. 191. 1957.

5. Silicates ind. T. XXH, núm. 6, pág. 336. 1957.

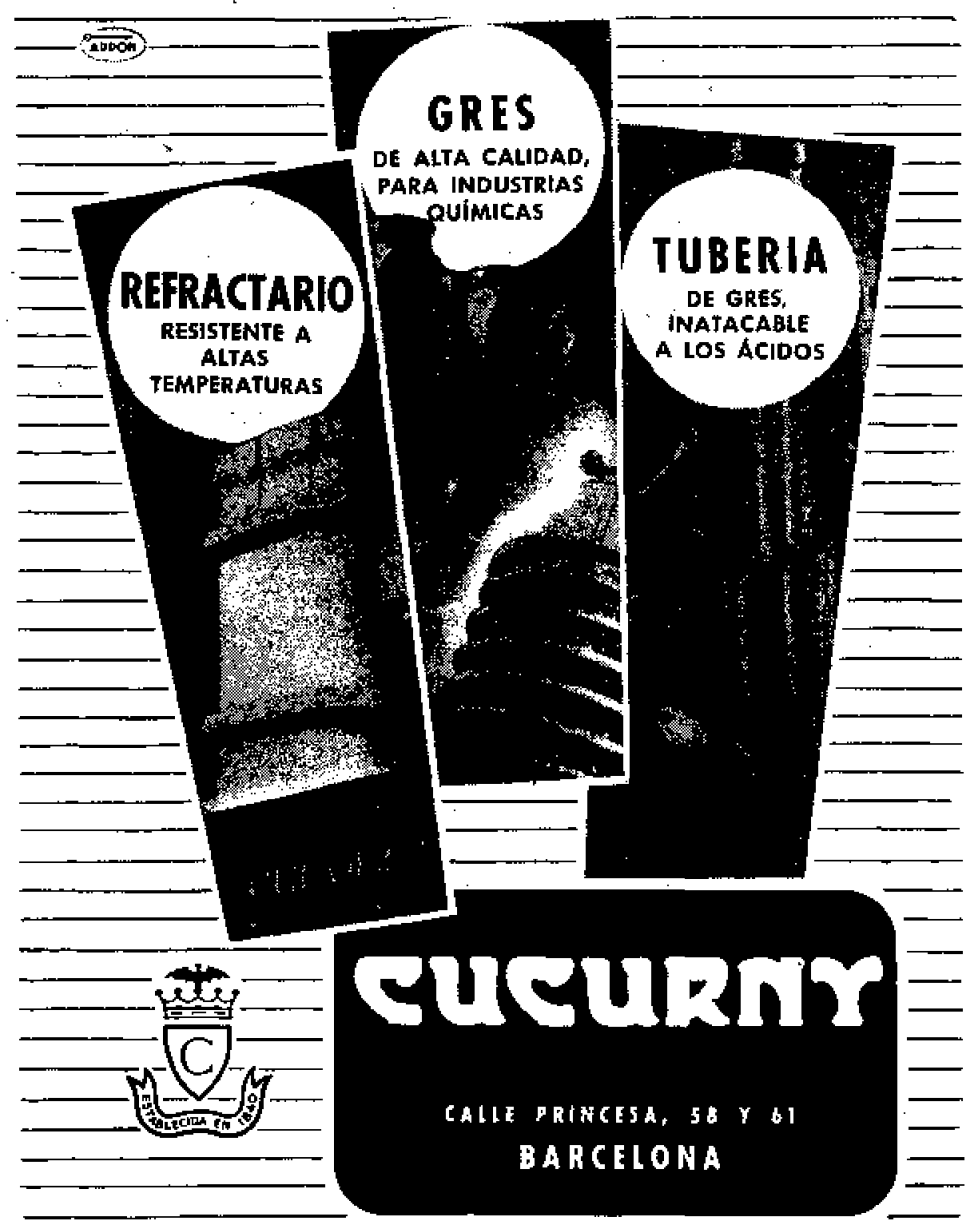

